\title{
Effect of Bronchoscopic Lung Volume Reduction in Advanced Emphysema on Energy Balance Regulation
}

\author{
Karin Sanders $^{\mathrm{a}} \quad$ Karin Klooster $^{\mathrm{b}} \quad$ Lowie E.G.W. Vanfleteren $^{\mathrm{c}}$ Guy Plasqui $^{\mathrm{d}}$ \\ Anne-Marie Dingemans ${ }^{\mathrm{e}}{ }^{\mathrm{f}}$ Dirk-Jan Slebos ${ }^{\mathrm{b}}$ Annemie M.W.J. Schols ${ }^{\mathrm{a}}$ \\ aDepartment of Respiratory Medicine, NUTRIM School of Nutrition and Translational Research in Metabolism, \\ Maastricht University Medical Centre, Maastricht, The Netherlands; ${ }^{b}$ Department of Pulmonary Diseases, University \\ of Groningen, University Medical Centre Groningen, Groningen, The Netherlands; 'COPD Centre, Institute of \\ Medicine, Sahlgrenska University Hospital, University of Gothenburg, Gothenburg, Sweden; dDepartment of Human \\ Biology and Movement Sciences, NUTRIM School of Nutrition and Translational Research in Metabolism, Maastricht \\ University Medical Centre, Maastricht, The Netherlands; 'Department of Pulmonary Diseases, GROW School \\ for Oncology and Developmental Biology, Maastricht University Medical Centre, Maastricht, The Netherlands; \\ fDepartment of Pulmonary Diseases, Erasmus Medical Center, Rotterdam, The Netherlands
}

\section{Keywords}

Emphysema · Lung volume reduction · Energy metabolism

\begin{abstract}
Background: Hypermetabolism and muscle wasting frequently occur in patients with severe emphysema. Improving respiratory mechanics by bronchoscopic lung volume reduction (BLVR) might contribute to muscle maintenance by decreasing energy requirements and alleviating eating-related dyspnoea. Objective: The goal was to assess the impact of BLVR on energy balance regulation. Design: Twenty emphysematous subjects participated in a controlled clinical experiment before and 6 months after BLVR. Energy requirements were assessed: basal metabolic rate (BMR) by ventilated hood, total daily energy expenditure (TDEE) by doubly labelled water, whole body fat-free mass (FFM) by deuterium dilution, and physical activity by accelerometry. Oxygen saturation, breathing rate, and heart rate were monitored before,
\end{abstract}

during, and after a standardized meal via pulse oximetry and dyspnoea was rated. Results: Sixteen patients completed follow-up, and among those, 10 patients exceeded the minimal clinically important difference of residual volume (RV) reduction. RV was reduced with median (range) 1,285 $\mathrm{mL}(-2,430$, $-540)$. Before BLVR, $90 \%$ of patients was FFM-depleted despite a normal BMI $\left(24.3 \pm 4.3 \mathrm{~kg} / \mathrm{m}^{2}\right)$. BMR was elevated by $130 \%$. TDEE/BMR was $1.4 \pm 0.2$ despite a very low median (range) daily step count of $2,188(739,7,110)$. Following BLVR, the components of energy metabolism did not change significantly after intervention compared to before intervention, but BLVR treatment decreased meal-related dyspnoea (4.1 vs. $1.7, p=0.019$ ). Conclusions: Impaired respiratory mechanics in hyperinflated emphysematous patients did not explain hypermetabolism. Clinical Trial Registry Number: NCT02500004 at www.clinicaltrial.gov.

(C) 2021 The Author(s)

Published by S. Karger AG, Basel
(C) 2021 The Author(s)

Published by S. Karger AG, Basel

This is an Open Access article licensed under the Creative Commons Attribution-NonCommercial-4.0 International License (CC BY-NC) (http://www.karger.com/Services/OpenAccessLicense), applicable to the online version of the article only. Usage and distribution for commercial purposes requires written permission.
Annemie M.W.J. Schols

Department of Respiratory Medicine, NUTRIM School of Nutrition and Translational Research in Metabolism, Maastricht University Medical Centre+ PO Box 616, NL -6200 Maastricht (The Netherlands) a.schols@maastrichtuniversity.nl 


\section{Introduction}

Only very recently, a new chronic obstructive pulmonary disease (COPD) phenotype titled "multi-organ loss of tissue" has been proposed. This phenotype includes those with accelerated emphysema progression and enhanced tissue loss in other extrapulmonary compartments, including muscle and adipose tissue. Disturbed tissue maintenance is associated with worse clinical outcomes [1] and might be the result of changes in whole body energy expenditure.

Whole-body energy expenditure can be distinguished into basal metabolic rate (BMR), diet-induced thermogenesis, and physical activity-induced energy expenditure. BMR is primarily determined by fat-free mass (FFM) and comprises the largest part of total daily energy expenditure (TDEE) [2]. Diet-induced thermogenesis is $\pm 10 \%$ of TDEE [3], and physical activity-induced energy expenditure largely depends on physical activity level [4]. Whole-body energy expenditure can only be measured over a prolonged period in daily life using doubly labelled water [5]. This stable isotope methodology is very expensive and requires analytical technology that is available in a limited number of centres worldwide.

In COPD, an increased BMR relative to predicted values has repeatedly been demonstrated [6], which is more aggravated in weight-losing patients [6] and in those with emphysema [7]. Although hypermetabolic at rest, COPD patients do not exhibit increased diet-induced thermogenesis [8]. Besides the proposed triggers for hypermetabolism including activation of brown adipose tissue, inflammation, and increased whole body protein turnover, impaired lung mechanics might also result in hypermetabolism [9]. Emphysema is hallmarked by a reduction in lung elastic recoil and progressive hyperinflation, resulting in elevated airway resistance and contributing to impaired lung mechanics [10]. This results in an increased workload of breathing ( $\mathrm{mL}$ oxygen cost per litre ventilation) [11]. The increased breathing workload has shown to be more pronounced in patients with low body weight and correlated with the degree of hyperinflation [12].

Pharmacological interventions may alleviate dyspnoea, reduce exercise limitation, and improve quality of life in COPD by decreasing airway resistance and reducing hyperinflation. However, response is limited in patients with predominant emphysema [13]. In selected severe emphysematous patients, bronchoscopic lung volume reduction (BLVR) is an additional treatment option that results in marked benefits in terms of pulmonary function, dyspnoea, exercise capacity, and also physical activity [14,
15]. Furthermore, in a recent post hoc analysis of the STELVIO trial [15], we illustrated a significant increase in body weight, skeletal muscle, and fat tissue, suggesting a positive effect on energy balance regulation [16].

BLVR is a unique model to test the influence of lung mechanics on energy balance regulation, as it diminishes thoracic hyperinflation, reduces breathing frequency, and reduces mechanical constraints on lung volume expansion, thereby improving ventilatory mechanics [17]. Efficacy of this treatment highly depends on advanced patient selection to identify responders to the treatment and thereby creating a homogeneous study population.

We hypothesize that a decline in breathing workload following BLVR would decrease energy expenditure, which might positively influence components and determinants of energy balance. Second, BLVR may also improve dietary intake by alleviating eating associated dyspnoea and meal-related oxygen desaturation [18].

\section{Methods}

\section{Participants}

Twenty patients with advanced emphysema, an identified target lobe with confirmed absence of collateral ventilation by the Chartis measurement, who underwent BLVR treatment using 1 -way endobronchial valves were included in this study. Patients were recruited from the Maastricht University Medical Centre (MUMC+) and University Medical Centre Groningen (UMCG) in the Netherlands from September 2016 until April 2017. The Ethics Committee of Maastricht University Medical Centre approved the study protocol, and all participants provided written informed consent. Procedures were conducted according to the principles of the Declaration of Helsinki. The trial was registered at ClinicalTrial.gov (NCT02500004).

\section{Study Design}

The study design is shown in Figure 1. Prior to BLVR treatment, patients underwent a 2 -week assessment period.

At day 0, patients were visited at home and received a dose of doubly labelled water. They were also instructed to collect urine samples for assessment of TDEE and to wear an accelerometer for registration of physical activity. Furthermore, patients were asked to record their dietary intake in order to assess if they were in a state of stable energy balance. On day 15, fasted-state urine and blood samples were collected; weight, height, and BMR were assessed; and a meal test was performed (vide infra). This 2-week assessment period was repeated 6 months after BLVR treatment.

\section{Body Composition}

Body height was determined to the nearest $0.5 \mathrm{~cm}$ while the subjects were standing barefoot. Weight was assessed with a beam scale to the nearest $0.1 \mathrm{~kg}$ while the subjects were standing barefoot and in light clothing. FFM was calculated from total body water assessment using the deuterium dilution technique, assuming a hydration fraction of FFM of $73 \%$. 


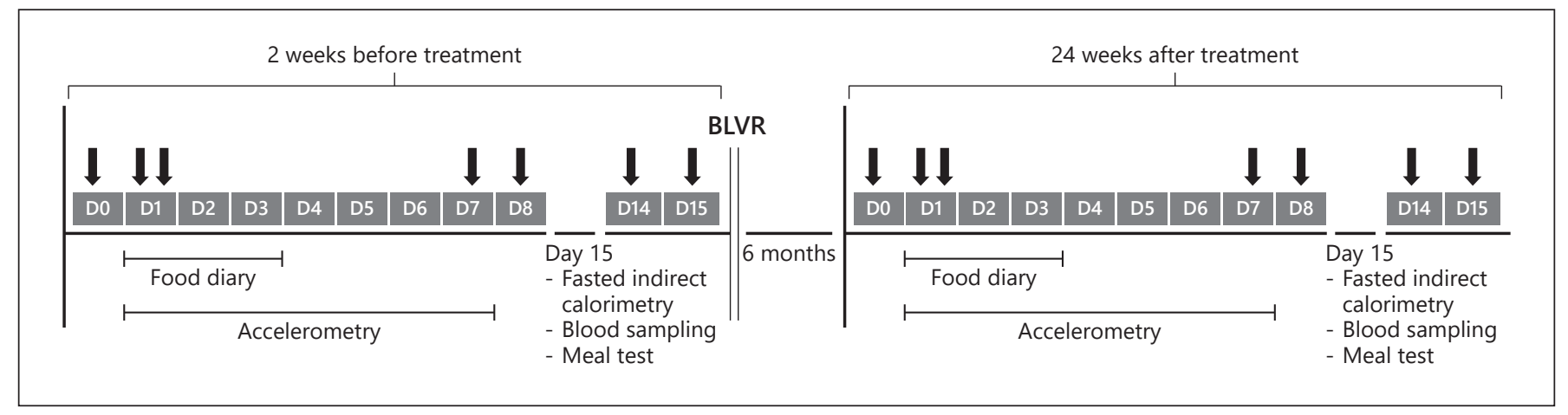

Fig. 1. Study design in days. Black arrows indicate urine sampling.

\section{Resting Metabolic Rate}

BMR was measured by indirect calorimetry using a ventilated hood (EZCAL; Maastricht Instruments, Maastricht, the Netherlands and COSMED QUARK; TulipMed B.V., The Netherlands). Patients received their maintenance inhalation according to their normal habits. The time interval between medication use and start of indirect calorimetry was documented. During the second 2-week assessment period 6 months following BLVR treatment, the same time interval between medication use and start of indirect calorimetry was employed. Patients were in a fasting state for at least $10 \mathrm{~h}$ and had a period of 30 -min bed rest prior to the measurement during which subjects were lying on bed in supine position. After stabilization, BMR was recorded during a period of $30 \mathrm{~min}$. BMR was calculated from oxygen consumption $\left(\mathrm{VO}_{2}\right)$ and carbon dioxide $\left(\mathrm{VCO}_{2}\right)$ production using the abbreviated Weir formula [19]. BMR was also predicted using the equation from Slinde et al. [20], which was especially designed for COPD patients.

\section{Total Daily Energy Expenditure}

TDEE was determined by the doubly labelled water technique over two 2-week periods (before and after BLVR treatment) according to the Maastricht protocol [21]. In the evening, prior to dosing, a urine sample was collected for determination of background isotope enrichment. Each patient received a weighted oral dose of water labelled with deuterium and oxygen-18. The given dose was calculated based on the subjects' total body water, which was estimated based on BMI, age, and gender. Subjects received a dose of $2.5 \mathrm{~g} / \mathrm{L}$ total body water containing $250 \mathrm{ppm}$ deuterium and 2,200 ppm oxygen-18. After overnight equilibration, a second urine sample was collected from the second morning voiding. Additional urine samples were collected in the evening of days 1,7 , and 14 and in the morning of days 8 and 15. TDEE was calculated by the linear regression from the difference between elimination constants of deuterium and oxygen-18.

\section{Physical Activity}

Actigraph GTX3 accelerometers (Actigraph, Pensacola, FL, USA) were used to assess the physical activity level. This activity monitor has been validated against activity-related energy expenditure measured by doubly labelled water in patients with different stages of COPD [22]. The triaxial accelerometers were attached to the lower back with an elastic belt and worn for 7 consecutive days. Subjects were instructed to wear the accelerometer during the time they were not asleep, except when showering or bathing. Only days with $\geq 8$ h of wear time were accepted as valid days. Energy expenditure for activities was calculated by $(0.9 \times$ TDEE $)-B M R$, assuming a diet-induced thermogenesis of $10 \%$ of TDEE.

\section{Dietary Intake}

Food intake was recorded by a food diary for 2 week days and 1 weekend day to estimate baseline energy balance.

\section{Meal Test}

On the measurement day at the hospital, subjects received a standardized breakfast with wheat bread, butter, eggs, and milk. This meal contained a total of $502 \mathrm{kcal}$ derived from protein (24\%), carbohydrate (28\%), and fat (48\%). Oxygen saturation, breathing rate, and heart rate were monitored before, during, and after the breakfast via pulse oximetry. Before and immediately after the meal, dyspnoea was rated using the Borg Dyspnoea Scale.

\section{Systemic Inflammatory Status}

High-sensitive C-reactive protein (hsCRP) was assessed from frozen stored plasma collected from a venepuncture after overnight fasting.

\section{Statistics}

Descriptive statistics of demographic and clinical variables were obtained. Means $( \pm S D)$ were provided for continuous normally distributed variables, medians (interquartile range) for continuous not normally distributed variables, and percentages were shown for categorical variables. Baseline and 6-month follow-up measurements were compared with a paired-sample $t$ test or Wilcoxon signed-rank test. All analyses were performed using SPSS statistical software (SPSS Statistics for Windows, version 24.0; IBM, Armonk, NY, USA). Results with 2 -sided $p$ values $(<0.05)$ were considered statistically significant.

\section{Results}

\section{Patient Characteristics}

Twenty patients (7 men, 13 women) with severe emphysema ( $n=10 \mathrm{MUMC}+$ and $n=10 \mathrm{UMCG}$ ) were enrolled in this study, and 16 patients completed the follow- 
Table 1. Baseline characteristics $(N=20)$

$\begin{array}{lc}\text { General } & \\ \text { Male/Female, } n & 7 / 13 \\ \text { Age, years } & 63 \pm 7 \\ \text { Pack, years } & 42 \pm 25 \\ \text { Lung function } & \\ \text { FEV }_{1}, \% \text { predicted } & 23.3 \pm 6.6 \\ \text { FVC, \% predicted }_{\text {FEV }} / \text { FVC } & 76.2 \pm 15.9 \\ \text { RV, \% predicted } & 28.5 \pm 6.3 \\ \text { TLC, \% predicted } & 238.3 \pm 38.2 \\ \text { RV/TLC } & 136.6 \pm 17.9 \\ \text { Body composition } & 64.7 \pm 9.4 \\ \text { Weight, kg } & \\ \text { BMI, kg/m } & 70.3 \pm 16.3 \\ \text { FFM, kg } & 24.1 \pm 4.4 \\ \text { FFMI, kg/m }{ }^{2} & 38.2(32.1-57.4) \\ \text { Male } & \\ \text { Female } & 15.1(14.7-16.2) \\ \end{array}$

Data are represented as mean \pm SD or median (minimum- $m$ aximum). $\mathrm{FEV}_{1}$, forced expiratory volume in $1 \mathrm{~s} ; \mathrm{FVC}$, forced vital capacity; RV, residual volume; TLC, total lung capacity; FFM, fatfree mass; FFMI, fat-free mass index.

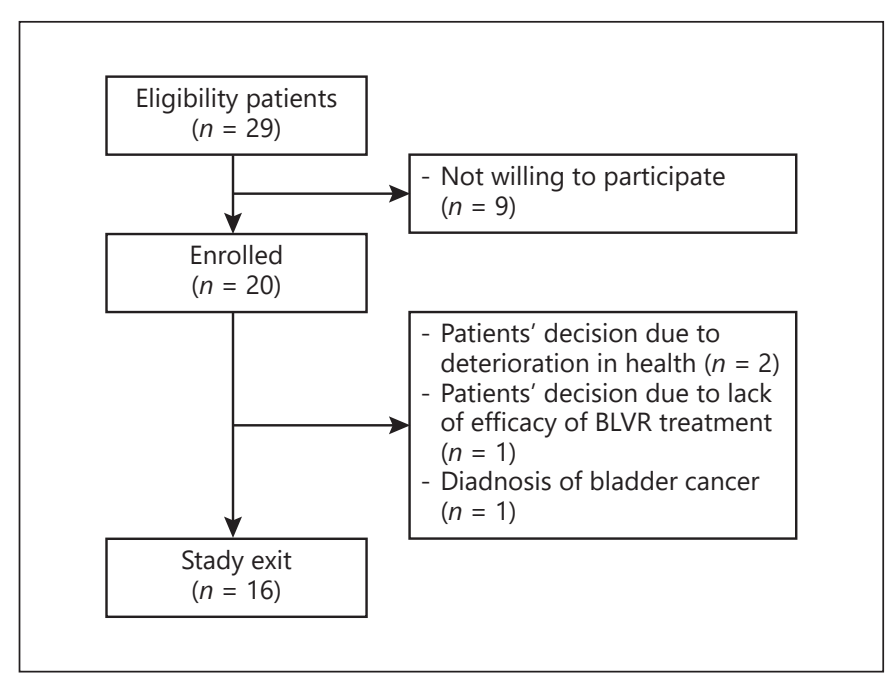

Fig. 2. Study flowchart.

up. Reasons for drop out were patients' decision due to deterioration in health $(n=2)$, patients' decision due to lack of efficacy of BLVR treatment $(n=1)$, and diagnosis of bladder cancer $(n=1)$. In 4 of the 16 patients who completed follow-up, endobronchial valves were removed due to granulation tissue around endobronchial valves $(n=2)$, torsion bronchus $(n=1)$, and recurrent pneumothorax $(n=1)$ (Fig. 2).
Baseline characteristics are depicted in Table 1. The study population represented a COPD population with normal BMI $\left(24.1 \pm 4.4 \mathrm{~kg} / \mathrm{m}^{2}\right)$ and low FFM (FFM index: males $15.1 \mathrm{~kg} / \mathrm{m}^{2}$ [14.7, 16.2], females $13.5 \mathrm{~kg} / \mathrm{m}^{2}$ [12.1, 18.1]). The prevalence of depletion of FFM, defined as FFM index $\leq 17 \mathrm{~kg} / \mathrm{m}^{2}$ for males or $\leq 15 \mathrm{~kg} / \mathrm{m}^{2}$ for females [23], was $90 \%$.

\section{Baseline Assessment}

At baseline, the mean BMR was 1,537 $\pm 259 \mathrm{kcal} /$ day, which corresponded to $130 \%$ of predicted, indicating pronounced hypermetabolism. The average TDEE over 2 weeks was $2,133 \pm 294 \mathrm{kcal} /$ day. The average daily TDEE of week 1 was not statistically significantly different from the average daily TDEE of week 2 . Energy expenditure for activities was median (range) $275 \mathrm{kcal} /$ day $(138,827)$ (11\% of TDEE).

Among those who completed follow-up, from all subjects but 2 (due to an accelerometer device defect), $6.5 \pm$ 1.1 valid accelerometry days were available with a mean of $13 \pm 1 \mathrm{~h}$ of wear time per day. Median (range) steps per day was $2,188(739,7,110)$. Patients spent a significant part of the day in sedentary state $(79.7 \%$ of the wear time $[56.5,89.6])$ (Table 2).

Systemic inflammation measured by hsCRP was $3.0 \pm$ $2.7 \mathrm{mg} / \mathrm{L}$. BMR or TDEE was not associated with hsCRP or residual volume (RV) (\% of predicted) (data not shown). Reported dietary intake comprised 2,065 \pm 507 $\mathrm{kcal} / 24 \mathrm{~h}$, which equalled measured TDEE. Patients experienced more dyspnoea after eating $(4.1 \pm 1.8$ after meal vs. $2.1 \pm 2.1$ before meal, $p=0.013$ ). No significant change was shown in oxygen saturation, respiration rate, and heart beat rate during the course of the meal (Fig. 3).

\section{Response after BLVR}

Not all patients benefited from the BLVR treatment, in terms of hyperinflation reduction. We therefore took a closer look at the 10 patients who responded beyond the MCID for RV reduction of $>430 \mathrm{~mL}$ [24]. At 6-month follow-up, patients significantly improved in RV and forced expiratory volume in $1 \mathrm{~s}$, with $1,285 \mathrm{~mL}(-2,430$, $-540)$ and $190 \mathrm{~mL}(10,390)$, respectively.

BMR did not significantly change over time $(1,537 \pm$ $259 \mathrm{kcal} /$ day vs. $1,549 \pm 231 \mathrm{kcal} /$ day, $p=0.778)$, and patients remained hypermetabolic (BMR was $130 \%$ of predicted). No changes in TDEE were observed $(2,133$ $\pm 294 \mathrm{kcal} /$ day vs. $2,192 \pm 480 \mathrm{kcal} /$ day, $p=0.576)$, in accordance with an unaltered physical activity expressed by mean number of daily steps. Although 6-min walk distance increased significantly, the mean step 
Table 2. Clinical variables and components of energy balance at baseline and 6 months after BLVR treatment $(n=10)$

\begin{tabular}{|c|c|c|c|}
\hline & Baseline & After BLVR & $p$ value \\
\hline \multicolumn{4}{|l|}{ Lung function and symptom burden } \\
\hline $\mathrm{FEV}_{1}, \%$ of predicted value & $27.5 \pm 6.9$ & $34.9 \pm 8.3$ & 0.003 \\
\hline FVC, \% of predicted value & $74.4 \pm 15.0$ & $95.1 \pm 17.1$ & $<0.001$ \\
\hline $\mathrm{FEV}_{1} / \mathrm{FVC}^{1}$ & $30.5 \pm 7.2$ & $29.5 \pm 5.6$ & 0.591 \\
\hline $\mathrm{RV}, \%$ of predicted value & $236.2 \pm 37.6$ & $181.3 \pm 27.5$ & $<0.001$ \\
\hline TLC, $\%$ of predicted value & $135.0 \pm 20.0$ & $125.1 \pm 14.7$ & 0.007 \\
\hline $\mathrm{RV} / \mathrm{TLC}$ & $65.8 \pm 6.2$ & $51.3 \pm 6.1$ & $<0.001$ \\
\hline COPD assessment test, points & $18.6 \pm 3.4$ & $14.3 \pm 5.8$ & 0.022 \\
\hline 6MWD, m & $378 \pm 98$ & $427 \pm 84$ & 0.030 \\
\hline \multicolumn{4}{|l|}{ Body composition } \\
\hline Weight, kg & $71.4 \pm 17.4$ & $73.0 \pm 18.7$ & 0.096 \\
\hline $\mathrm{BMI}, \mathrm{kg} / \mathrm{m}^{2}$ & $24.3 \pm 4.3$ & $24.8 \pm 5.0$ & 0.127 \\
\hline FFM, kg & $40.4(32.2-57.4)$ & $41.1(29.4-60.2)$ & 0.074 \\
\hline \multicolumn{4}{|l|}{ FFMI, $\mathrm{kg} / \mathrm{m}^{2}$} \\
\hline Male & $15.5(14.7-16.2)$ & $16.6(15.5-18.6)$ & 0.068 \\
\hline Female & $13.2(12.4-17.6)$ & $13.6(12.1-17.3)$ & 0.600 \\
\hline \multicolumn{4}{|l|}{ Energy expenditure } \\
\hline $\mathrm{VCO}_{2}, \mathrm{~mL} / \mathrm{min}$ & $179.5 \pm 26.1$ & $180.5 \pm 28.6$ & 0.854 \\
\hline $\mathrm{VO}_{2}, \mathrm{~mL} / \mathrm{min}$ & $224.7 \pm 40.0$ & $224.0 \pm 3.1$ & 0.903 \\
\hline $\mathrm{RQ}$ & $0.81 \pm 0.07$ & $0.81 \pm 0.05$ & 0.916 \\
\hline BMR measured, kcal/day & $1,537 \pm 259$ & $1,549 \pm 231$ & 0.778 \\
\hline $\mathrm{BMR}$ predicted, $\mathrm{kcal} /$ day & $1,213 \pm 155$ & $1,245 \pm 189$ & 0.103 \\
\hline BMR measured/BMR predicted ratio & $1.3 \pm 0.2$ & $1.2 \pm 0.1$ & 0.655 \\
\hline TDEE, $\mathrm{kcal} / 24 \mathrm{~h}$ & $2,133 \pm 294$ & $2,192 \pm 480$ & 0.576 \\
\hline TDEE/BMR ratio & $1.4 \pm 0.2$ & $1.4 \pm 0.3$ & 0.934 \\
\hline Energy expenditure for activities, kcal/day & $275(138-827)$ & $397(18-1,262)$ & 0.694 \\
\hline Energy expenditure for activities/TDEE ratio & $0.2 \pm 0.1$ & $0.2 \pm 0.1$ & 0.995 \\
\hline \multicolumn{4}{|l|}{ Physical activity level } \\
\hline Mean steps/day & $2,188(739-7,110)$ & $2,429(990-6,983)$ & 0.161 \\
\hline Time spent in sedentary PA, \% of wear time & $79.7(56.5-89.6)$ & $79.4(52.7-84.2)$ & 0.123 \\
\hline Time spent in lifestyle PA, \% of wear time & $17.6(10.1-34.2)$ & $18.6(14.1-37.9)$ & 0.123 \\
\hline Time spent in MVPA, \% of wear time & $0.0(0.0-1.1)$ & $0.2(0.0-1.4)$ & 0.028 \\
\hline \multicolumn{4}{|l|}{ Inflammation } \\
\hline hsCRP, mg/L & $3.0 \pm 2.7$ & $2.5 \pm 1.8$ & 0.463 \\
\hline \multicolumn{4}{|c|}{$\begin{array}{l}\text { Data are represented as mean } \pm \mathrm{SD} \text {, or median (minimum-maximum). Values in bold are statistically sig- } \\
\text { nificant. COPD Assessment Test, missing } n=2 \mathrm{FEV}_{1} \text {, forced expiratory volume in } 1 \mathrm{~s} \text {; FVC, forced vital capac- } \\
\text { ity; RV, residual volume; TLC, total lung capacity; FFM, fat-free mass; FFMI, fat-free mass index; } 6 \mathrm{MWD}, 6-\mathrm{min} \\
\text { walk distance; MVPA, moderate-to-vigorous physical activity; PA, physical activity; BMR, basal metabolic rate; } \\
\text { TDEE, total daily energy expenditure; hsCRP, high-sensitive C-reactive protein. }\end{array}$} \\
\hline
\end{tabular}

count and activity-induced energy expenditure did not change over time. hsCRP also remained unchanged (Table 2).

A significant effect of BLVR treatment on meal-related dyspnoea was observed. Compared to baseline, meal-related dyspnoea after the meal was significantly lower after BLVR treatment $(1.7 \pm 2.4$ vs. $4.1 \pm 1.8, p=0.019)$. No changes were found in oxygen saturation, respiration rate, or heart rate during the meal (Fig. 3).

Energy Balance Following Lung Volume Reduction

\section{Discussion}

This is the first study presenting a comprehensive analysis of energy balance in a homogeneous group of patients with severe emphysema and investigating the effect of BLVR. In contrast to our hypothesis, a median reduction of hyperinflation with $25 \%$ did not decrease BMR or TDEE adjusted for physical activity level. Eating-related dyspnoea, however, was diminished. 


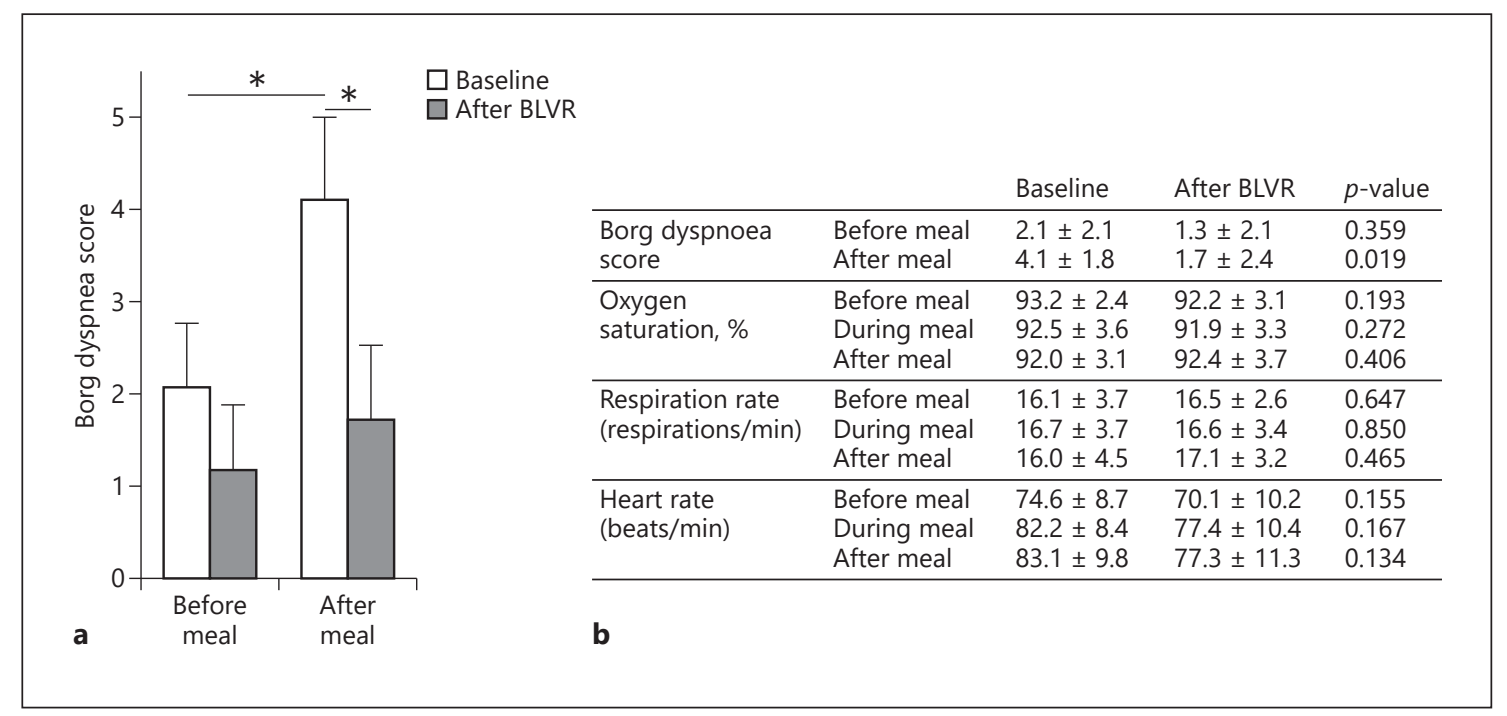

Fig. 3. Borg Dyspnoea Score (a), Borg Dyspnoea Score, oxygen saturation, respiration rate, and heart rate before, during, and after completion of a standardized meal, before, and after bronchoscopic lung volume reduction (BLVR) treatment $(n=10)(\mathbf{b})$. Data are presented as mean values ( \pm standard deviation).

In line with the "multiorgan loss of tissue" phenotype [1], we observed a very high prevalence of FFM depletion indicative for disturbed muscle maintenance. Nearly all patients were FFM-depleted, but this was disproportionate to the FM as the majority of patients fell within a normal BMI range. Before BLVR, BMR was very high, up to $130 \%$ of predicted and energy expenditure for physical activities was very low (11\%). This implies that in this patient group and at this stage of the disease, fat mass regulation is primarily determined by the balance between energy intake and whole body energy requirements and less or not yet by fat catabolism (i.e., increased lipolysis or brown adipose tissue activation). The normal BMI in this population hides FFM depletion, emphasizing the importance of body composition assessment for estimation of metabolic risk as proposed by the European Respiratory Society Task Force on nutritional assessment and therapy in COPD [25].

No studies to date have investigated the effect of lung volume reduction on TDEE, but a few studies previously reported the effect of lung volume reduction surgery on BMR. Mineo et al. [26] showed a reduction of BMR with $5 \%$, while Takayama et al. [27] observed no change in BMR. The degree of hyperinflation reduction was comparable to our cohort. Nevertheless, one needs to consider that although our patients improved importantly after intervention, they still remain severely hyperinflated with a mean RV of $181 \%$ of predicted.
A contributor to BMR is whole body protein turnover, which explained approximately $20 \%$ of the between-subject variation of BMR in healthy young individuals [28]. Also in COPD, increased rates of whole body protein turnover have been reported [29,30], which is associated with BMR [31]. Increased muscle turnover signalling was accompanied with elevated myogenic signalling [32], which was most prominent in patients with FFM depletion. Therefore, persistence of high BMR after BLVR might be the result of energy cost of protein anabolism, supported by increased muscle mass observed previously in chest CT scans [16].

In the absence of catabolic drivers, fat mass is primarily regulated by the balance between energy intake and energy metabolism. In line with others [33, 34], our patients experienced an eating induced increase in dyspnoea. Vermeeren et al. [33] reported the effects of different meals on dyspnoea sensation and found a significantly greater increase in dyspnoea after ingestion of a fat-rich meal than after a carbohydrate-rich meal. Here, we show for the first time that dyspnoea after the same, standardized meal was significantly less following BLVR. In line with 2 other studies, these effects could not be explained by changes in meal-related oxygen saturation $[18,33]$.

Systemic inflammation has been proposed as putative trigger for hypermetabolism, in particular during acute exacerbations $[35,36]$. Indeed, elevated CRP levels have previously been associated with higher BMR in clinically 
stable COPD [37, 38]. In this study, CRP levels were slightly elevated but did not change after BLVR.

The strength of this prospective well-controlled clinical proof of concept study comes from the well-defined patient cohort and from the use of gold standard methods to assess body composition, BMR, and TDEE. We recognize that the study power was based on detection of changes in energy metabolism in relation to changes in lung function but not on changes in body composition. The technique of pulse oximetry has the advantage of providing a continuous and non-invasive measurement of oxygen saturation. However, this technique is limited by a poorer accuracy of $1-3 \%$ when compared to arterial blood sampling [39]. To conclude, the present work showed that impaired respiratory mechanics in hyperinflated emphysematous patients did not explain hypermetabolism.

\section{Acknowledgements}

The authors would like to thank Dr. Coby Eelderink and Prof. Dr. Stephan J.L. Bakker from the University Medical Center Groningen for providing the use of the COSMED QUARK.

\section{Statement of Ethics}

The Ethics Committee of Maastricht University Medical Centre approved the study protocol, and all participants provided written informed consent before initiation of study measurements.
Procedures were conducted according to the principles of the Declaration of Helsinki. The trial was registered at ClinicalTrial.gov (NCT02500004).

\section{Conflict of Interest Statement}

K.J.C.S., L.E.G.W.V., G.P., and A.M.W.J.S. had nothing to disclose. K.K. reports grants, personal fees, non-financial support, and other from PneumRx/BTG (Mountain View, CA, USA), and grants, personal fees, non-financial support, and other from PulmonX (Redwood City, CA, USA), outside the submitted work. A.M.C.D. reports personal fees from Roche, Boehringer Ingelheim, Eli Lily, Novartis, Takeda, and BMS, outside the submitted work. D.J.S. reports grants, personal fees, non-financial support , and other from PulmonX Inc. (Redwood City, CA, USA), outside the submitted work.

\section{Funding Sources}

This analysis was part of the SOLVE project, funded by the Dutch Lung Foundation (Longfonds) (No. 5.1.17.171).

\section{Author Contributions}

A.M.W.J.S., L.E.G.W.V., and D.J.S. designed research; K.J.C.S. and K.K. conducted research; G.P., K.J.C.S., K.K., and A.M.W.J.S. analysed data; K.J.C.S. performed statistical analysis; K.J.C.S. and A.M.W.J.S. wrote the paper with input from K.K., L.E.G.W.V., G.P., A.-M.C.D., and D.J.S.; and all authors read and approved the final manuscript. K.J.C.S. had primary responsibility for the final content.

\section{References}

1 Celli BR, Locantore N, Tal-Singer R, Riley J, Miller B, Vestbo J, et al. Emphysema and extrapulmonary tissue loss in COPD: a multiorgan loss of tissue phenotype. Eur Respir J. 2018;51(2):1702146.

2 Wang Z, Heshka S, Gallagher D, Boozer CN, Kotler DP, Heymsfield SB. Resting energy expenditure-fat-free mass relationship: new insights provided by body composition modeling. Am J Physiol Endocrinol Metab. 2000; 279(3):E539-45.

3 Westerterp KR. Diet induced thermogenesis. Nutr Metab. 2004;1(1):5.

4 Pannemans DL, Westerterp KR. Energy expenditure, physical activity and basal metabolic rate of elderly subjects. Br J Nutr. 1995; 73(4):571-81.

5 Schoeller DA, Ravussin E, Schutz Y, Acheson KJ, Baertschi P, Jéquier E. Energy expenditure by doubly labeled water: validation in humans and proposed calculation. Am J Physiol. 1986; 250(5 Pt 2):R823-30.

Energy Balance Following Lung Volume Reduction
6 Schols AM, Soeters PB, Mostert R, Saris WH, Wouters EF. Energy balance in chronic obstructive pulmonary disease. Am Rev Respir Dis. 1991;143(6):1248-52.

7 Cohen RI, Marzouk K, Berkoski P, O’Donnell CP, Polotsky VY, Scharf SM. Body composition and resting energy expenditure in clinically stable, non-weight-losing patients with severe emphysema. Chest. 2003;124(4):136572.

8 Hugli O, Frascarolo P, Schutz Y, Jéquier E, Leuenberger P, Fitting JW. Diet-induced thermogenesis in chronic obstructive pulmonary disease. Am Rev Respir Dis. 1993;148(6 Pt 1):1479-83.

9 Sanders KJ, Kneppers AE, van de Bool C, Langen RC, Schols AM. Cachexia in chronic obstructive pulmonary disease: new insights and therapeutic perspective. J Cachexia Sarcopenia Muscle. 2016;7(1):5-22.

10 Criner GJ, Cordova F, Sternberg AL, Martinez FJ. The National Emphysema Treatment
Trial (NETT): part I: lessons learned about emphysema. Am J Respir Crit Care Med. 2011;184(7):763-70.

11 Cherniack RM. The oxygen consumption and efficiency of the respiratory muscles in health and emphysema. J Clin Invest. 1959;38(3): 494-9.

12 Donahoe M, Rogers RM, Wilson DO, Pennock BE. Oxygen consumption of the respiratory muscles in normal and in malnourished patients with chronic obstructive pulmonary disease. Am Rev Respir Dis. 1989;140(2):385-91.

13 O'Donnell DE, Flüge T, Gerken F, Hamilton A, Webb K, Aguilaniu B, et al. Effects of tiotropium on lung hyperinflation, dyspnoea and exercise tolerance in COPD. Eur Respir J. 2004;23(6):832-40.

14 Hartman JE, Klooster K, Slebos DJ, Ten Hacken NH. Improvement of physical activity after endobronchial valve treatment in emphysema patients. Respir Med. 2016;117:11621. 
15 Klooster K, ten Hacken NH, Hartman JE, Kerstjens HA, van Rikxoort EM, Slebos DJ. Endobronchial valves for emphysema without interlobar collateral ventilation. N Engl J Med. 2015;373(24):2325-35.

16 Sanders KJC, Klooster K, Vanfleteren L, Slebos DJ, Schols A. CT-derived muscle remodelling after bronchoscopic lung volume reduction in advanced emphysema. Thorax. 2019 Feb;74(2):206-7.

17 O'Donnell DE, Webb KA, Bertley JC, Chau LK, Conlan AA. Mechanisms of relief of exertional breathlessness following unilateral bullectomy and lung volume reduction surgery in emphysema. Chest. 1996;110(1):18-27.

18 Schols A, Mostert R, Cobben N, Soeters P, Wouters E. Transcutaneous oxygen saturation and carbon dioxide tension during meals in patients with chronic obstructive pulmonary disease. Chest. 1991;100(5):1287-92.

19 Weir JB. New methods for calculating metabolic rate with special reference to protein metabolism. 1949. Nutrition. 1990;6(3):21321.

20 Slinde F, Ellegård L, Grönberg AM, Larsson S, Rossander-Hulthén L. Total energy expenditure in underweight patients with severe chronic obstructive pulmonary disease living at home. Clin Nutr. 2003;22(2):159-65.

21 Westerterp KR, Wouters L, van Marken Lichtenbelt WD. The Maastricht protocol for the measurement of body composition and energy expenditure with labeled water. Obes Res. 1995;3(Suppl 1):49-57.

22 Rabinovich RA, Louvaris Z, Raste Y, Langer D, Van Remoortel H, Giavedoni S, et al. Validity of physical activity monitors during daily life in patients with COPD. Eur Respir J. 2013;42(5):1205-15.

23 Vestbo J, Prescott E, Almdal T, Dahl M, Nordestgaard BG, Andersen T, et al. Body mass, fat-free body mass, and prognosis in patients with chronic obstructive pulmonary disease from a random population sample: findings from the Copenhagen City Heart Study. Am J Respir Crit Care Med. 2006;173(1):79-83.

24 Hartman JE, Ten Hacken NH, Klooster K, Boezen HM, de Greef MH, Slebos DJ. The minimal important difference for residual volume in patients with severe emphysema. Eur Respir J. 2012;40(5):1137-41.

25 Schols AM, Ferreira IM, Franssen FM, Gosker HR, Janssens W, Muscaritoli M, et al. Nutritional assessment and therapy in COPD: a European Respiratory Society statement. Eur Respir J. 2014;44(6):1504-20.

26 Mineo TC, Pompeo E, Mineo D, Ambrogi V, Ciarapica D, Polito A. Resting energy expenditure and metabolic changes after lung volume reduction surgery for emphysema. Ann Thorac Surg. 2006;82(4):1205-11.

27 Takayama T, Shindoh C, Kurokawa Y, Hida W, Kurosawa $\mathrm{H}$, Ogawa $\mathrm{H}$, et al. Effects of lung volume reduction surgery for emphysema on oxygen cost of breathing. Chest. 2003; 123(6): $1847-52$.

28 Welle S, Nair KS. Relationship of resting metabolic rate to body composition and protein turnover. Am J Physiol. 1990;258(6 Pt 1): E990-8.

29 Engelen MP, Deutz NE, Wouters EF, Schols AM. Enhanced levels of whole-body protein turnover in patients with chronic obstructive pulmonary disease. Am J Respir Crit Care Med. 2000;162(4 Pt 1):1488-92.

30 Morrison WL, Gibson JN, Scrimgeour C, Rennie MJ. Muscle wasting in emphysema. Clin Sci. 1988;75(4):415-20.

31 Kao CC, Hsu JW, Bandi V, Hanania NA, Kheradmand F, Jahoor F. Resting energy expenditure and protein turnover are increased in patients with severe chronic obstructive pulmonary disease. Metab Clin Exp. 2011; 60(10):1449-55.
32 Kneppers AEM, Langen RCJ, Gosker HR, Verdijk LB, Cebron Lipovec N, Leermakers $\mathrm{PA}$, et al. Increased myogenic and protein turnover signaling in skeletal muscle of chronic obstructive pulmonary disease patients with sarcopenia. J Am Med Dir Assoc. 2017;18(7):637.e1-e11.

33 Vermeeren MA, Wouters EF, Nelissen LH, van Lier A, Hofman Z, Schols AM. Acute effects of different nutritional supplements on symptoms and functional capacity in patients with chronic obstructive pulmonary disease. Am J Clin Nutr. 2001;73(2):295-301.

34 Wolkove N, Fu LY, Purohit A, Colacone A, Kreisman H. Meal-induced oxygen desaturation and dyspnea in chronic obstructive pulmonary disease. Can Respir J. 1998;5(5): 361-5.

35 Hopkinson NS, Tennant RC, Dayer MJ, Swallow EB, Hansel TT, Moxham J, et al. A prospective study of decline in fat free mass and skeletal muscle strength in chronic obstructive pulmonary disease. Respir Res. 2007;8:25.

36 Rutten EP, Spruit MA, McDonald ML, Rennard S, Agusti A, Celli B, et al. Continuous fat-free mass decline in COPD: fact or fiction? Eur Respir J. 2015;46(5):1496-8.

37 Broekhuizen R, Wouters EF, Creutzberg EC, Schols AM. Raised CRP levels mark metabolic and functional impairment in advanced COPD. Thorax. 2006;61(1):17-22.

38 Schols AM, Buurman WA, Staal van den Brekel AJ, Dentener MA, Wouters EF. Evidence for a relation between metabolic derangements and increased levels of inflammatory mediators in a subgroup of patients with chronic obstructive pulmonary disease. Thorax. 1996;51(8):819-24.

39 Nickerson BG, Sarkisian C, Tremper K. Bias and precision of pulse oximeters and arterial oximeters. Chest. 1988;93(3):515-7. 